\title{
SUPERAÇÃO DA DORMÊNCIA EM SEMENTES DE Caesalpinia pyramidalis Tul $^{1}$
}

\author{
Edna Ursulino Alves ${ }^{2}$, Edson de Almeida Cardoso ${ }^{3}$, Riselane de Lucena Alcântara Bruno ${ }^{2}$, Adriana \\ Ursulino Alves ${ }^{4}$, Anarlete Ursulino Alves ${ }^{5}$, Evio Alves Galindo ${ }^{3}$ Joel Martins Braga Junior ${ }^{3}$
}

\begin{abstract}
RESUMO - Espécies florestais com sementes duras freqüentemente apresentam consideráveis problemas para os viveiristas, porque seus tegumentos duros e impermeáveis à água dificultam e retardam a germinação. Por isso, desenvolveu-se este experimento em casa de vegetação no Centro de Ciências Agrárias da Universidade Federal da Paraíba, com o objetivo de determinar metodologias para superar a dormência de sementes de catingueira. O delineamento experimental adotado foi o inteiramente ao acaso, com quatro repetições de 25 sementes. As sementes foram submetidas a 12 tratamentos: testemunha - sementes intactas $\left(\mathrm{T}_{1}\right)$, escarificação mecânica feita manualmente com lixa $\mathrm{n}^{\circ} .80\left(\mathrm{~T}_{2}\right)$, desponte - pequeno corte na região oposta à micrópila $\left(\mathrm{T}_{3}\right)$, imersão no ácido sulfúrico concentrado por 6,8 e $10 \mathrm{~min}\left(\mathrm{~T}_{4}, \mathrm{~T}_{5} \mathrm{e} \mathrm{T}_{6}\right.$, respectivamente), imersão em água nas temperaturas de 60,70 e $80{ }^{\circ} \mathrm{C}$ por $1 \mathrm{~min}\left(\mathrm{~T}_{7}, \mathrm{~T}_{8}\right.$ e $\mathrm{T}_{9}$, respectivamente) e imersão em água fria por 24,48 e $72 \mathrm{~h}\left(\mathrm{~T}_{10}\right.$, $\mathrm{T}_{11}$ e $\mathrm{T}_{12}$, respectivamente). As sementes foram semeadas em bandejas plásticas com areia umedecida esterilizada. Através de avaliações diárias durante 21 dias, verificaram-se as características de porcentagem de emergência, primeira contagem de emergência, índice de velocidade de emergência, comprimento e massa seca das plântulas. Os resultados evidenciaram que os tratamentos pré-germinativos promoveram a germinação das sementes de catingueira, e a escarificação manual com lixa, imersão em ácido sulfúrico concentrado por 8 e 10 min e imersão em água a $80^{\circ} \mathrm{C}$ por 1 min revelaram ser os métodos mais efetivos.
\end{abstract}

Palavras-chave: Catingueira, germinação e vigor.

\section{OVERCOMING DORMANCY OF Caesalpinia pyramidalis Tul}

\begin{abstract}
Forest species with hard seeds often cause important problems for nursery managers because their hard and water impermeable seed coats hinder and delay germination. For this reason, an experiment was carried out to determine methodologies for overcoming dormancy of catingueira seeds, under greenhouse conditions, in the Center for Agricultural Sciences, of the Federal University of Paraíba. The experiment was arranged in a complete randomized design, with four replicates of 25 seeds/treatment. Seeds were subjected to 12 treatments: control - intact seeds $\left(T_{1}\right)$, mechanical scarification using fine sandpaper $n^{o} .80\left(T_{2}\right)$, coating cutting in the opposite side of micropylar region $\left(T_{3}\right)$, immersion in sulfuric acid (98\%) for 6,8 and 10 minutes ( $T_{4}, T_{5}$ and $T_{6}$, respectively), immersion in water at 60,70 and $80^{\circ} \mathrm{C}$ for one minute $\left(T_{7}, T_{8}\right.$ and $T_{9}$, respectively), immersion in water at room temperature for 24,48 and 72 hours $\left(T_{10}, T_{11}\right.$ and $T_{12}$, respectively). The seeds
\end{abstract}

\footnotetext{
${ }^{1}$ Recebido em 31.08.2006 e aceito para publicação em 17.04.2007.

${ }_{2}^{2}$ Departamento de Fitotecnia. CCA-UFPB, Areia-PB. Caixa Postal 02, 58.397-000 Areia-PB. E-mail: <ednaursulino@cca.ufpb.br>.

${ }^{3}$ Graduação em Agronomia. CCA-UFPB, Areia-PB.

${ }^{4}$ Programa de Pós-Graduação em Agronomia da UNESP-Jaboticabal-SP.

${ }^{5}$ Programa de Pós-Graduação em Agronomia da UFPB, Areia-PB.
} 
were sown in plastic trays with sterilized humidified sand. Daily evaluations were carried out during 21 days observing characteristics of emergence percentage, emergence first count, emergence velocity index, height and dry matter weight of seedlings. The results demonstrated that germinative pre-treatments increased seed germination of catingueira seeds, and higher values were observed with manual scarification with sandpaper, immersion in concentrated sulfuric acid during eight and ten minutes and immersion in water at $80^{\circ} \mathrm{C}$ for one minute were the most effective methods.

Keywords: Catingueira, germination and vigor.

\section{INTRODUÇÃO}

Apesar de as espécies nativas no Brasil apresentarem alto potencial de utilização, quer seja pelo seu valor ornamental, madeireiro e alimentício, quer seja pelo seu valor de preservação, pouca atenção vinha sendo dada a elas (CARVALHO et al., 1980). Tal fato se devia, provavelmente, à falta de interesse dos viveiristas por essas espécies e às dificuldades na obtenção de suas sementes, uma vez que não existia comércio para elas (NASSIF e PEREZ, 1997). A espécie arbórea Caesalpinia pyramidalis Tul., pertencente à família Leguminosae, subfamília Caesalpinoideae, popularmente conhecida como catingueira, é uma das que se encontram nessa condição e até hoje foi pouco estudada.

A produção de sementes florestais, principalmente no Nordeste brasileiro, tem-se constituído, nos últimos anos, numa das maiores dificuldades para implantação de plantios florestais, seja para obtenção de produtos diversos como lenha, carvão, madeira para serrarias, cercas, moirões e alimento para gado, seja para melhorar a qualidade dos solos e das águas (IBAMA, 1998). A devastação das florestas nativas no Brasil está levando à extinção de muitas espécies, além de provocar incalculáveis prejuízos à população, por forçar um equilíbrio ecológico para os quais ela não foi preparada.

Caesalpinia pyramidalis Tul. é uma espécie de ampla dispersão no Nordeste semi-árido, podendo ser encontrada em diversas associações vegetais, crescendo bem nas várzeas úmidas, onde chega a atingir mais de $10 \mathrm{~m}$ e poucos centímetros de diâmetro na base. Ocorre nos Estados do Piauí, Ceará, Rio Grande do Norte, Paraíba, Pernambuco, Alagoas, Sergipe e Bahia, sendo considerada endêmica da caatinga (MAIA, 2004).

Essa espécie é uma planta característica da caatinga que vegeta em lugares pedregosos (PIO CORRÊA, 1984). A madeira é recomendada para lenha, carvão e estaca.
É uma das plantas sertanejas cujos gomos brotam nas primeiras manifestações de umidade, portanto é uma anunciadora do período das chuvas. As folhas fenadas constituem boa forragem, e as flores, folhas e cascas são usadas no tratamento das infecções catarrais e nas diarréias (BRAGA, 1976).

Na agricultura, é desejável que as sementes de uma espécie tenham germinação rápida e uniforme. Contudo, mesmo sob condições ótimas de umidade, luz, temperatura e oxigênio, algumas espécies apresentam retardamento e, ou, desuniformidade na germinação devido ao fenômeno da dormência (SOUZA et al., 1980). Segundo Popinigis (1985), a dormência evoluiu como um mecanismo de sobrevivência das espécies em determinadas condições climáticas. O conhecimento das causas da incapacidade germinativa é importante para se encontrarem meios de superá-las (BIANCHETTI e RAMOS, 1981). Carvalho e Nakagawa (2000) afirmaram que a dormência de sementes de plantas cultivadas é atribuída, usualmente, a tegumentos impermeáveis, à imaturidade fisiológica ou à colheita recente.

A impermeabilidade do tegumento à água é um tipo de dormência bastante comum e está associada a espécies de diversas famílias botânicas, sendo constatada com maior frequiência em sementes de espécies de Leguminosae, Malvaceae, Geraniaceae, Chenopodiaceae, Convolvulaceae, Solanaceae e Liliaceae (KRAMER e KOZLOWSKI, 1972; POPINIGIS, 1985; CÍCERO, 1986). Segundo Carvalho e Nakagawa (2000), esse tipo de dormência é encontrado com maior freqüência em Leguminosae. Conforme levantamento realizado por Rolston (1978), de 260 espécies de leguminosas examinadas, cerca de $85 \%$ apresentavam sementes com tegumento total ou parcialmente impermeável à água.

Em ambiente natural, essa dormência é superada por processos de escarificação, a qual consiste em 
qualquer tratamento que resulte na ruptura ou enfraquecimento do tegumento, permitindo a entrada de água e gases e, assim, dando início ao processo germinativo (MAYER e POLJAKOFF-MAYBER, 1989). Nesse ambiente, a escarificação pode ocorrer pelo aquecimento úmido ou seco do solo por temperaturas alternadas, permitindo, assim, a entrada de água para o interior da semente. Esse processo pode ocorrer, também, pela ação de ácidos durante a ingestão das sementes por animais dispersores, além da ação dos microrganismos do solo (VAZQUEZ-YANES e OROZCOSEGOVIA, 1993).

Em laboratório foram desenvolvidos diversos métodos, visando à superação desse tipo de dormência, como as escarificações química e mecânica, a estratificação, o choque térmico, a exposição à luz intensa, a imersão em águas quente e fria, entre outros (LOPES et al., 1998, 2006; ALVES et al., 2000, 2004, 2006; SMIDERLE et al., 2005). No entanto, a aplicabilidade e eficiência desses tratamentos dependem do tipo e grau de dormência, que variam entre as espécies.

A escarificação mecânica foi o método mais eficiente para superação da dormência de sementes de Pterogyne nitens Tul. (NASSIF e PEREZ, 1997), Leucaena diversifolia (Schlecht.) Benth. K156 (BERTALOT e NAKAGAWA, 1998), Operculina macrocarpa (MEDEIROS FILHO et al., 2002) e Ormosia nitida Vog. (LOPES et al., 2006).

Os tratamentos de escarificações mecânica e química com ácido sulfúrico entre 5 e 60 min foram responsáveis pelas maiores porcentagens de germinação das sementes de Caesalpinea ferrea Mart. ex Tul. var. leiostachya Benth., Cassia grandis L. e Samanea saman Merrill. (LOPES et al., 1998). Para superar a dormência das sementes de Bauhinia monandra Britt. e de Bauhinia ungulata L., os tratamentos mais eficientes foram imersão em ácido sulfúrico por 20 min e escarificação mecânica do tegumento, respectivamente (ALVES et al., 2000). Smiderle e Souza (2003) também indicaram a escarificação com ácido sulfúrico por $5 \mathrm{~min}$ para superação da dormência de sementes de Bowdichia virgilioides Kunth.

As sementes de Ochroma lagopus SW. germinaram melhor e mais rápido quando tratadas com água à temperatura de $80^{\circ} \mathrm{C}$ até o resfriamento ou com ácido sulfúrico por $1 / 2$ ou 1 min (BARBOSA et al., 2004). Para as de Bauhinia divaricata L., Alves et al. (2004) recomendaram o desponte na região oposta à micrópila, enquanto a emergência máxima de plântulas de Acacia mangium foi obtida após o tratamento das sementes em água a $100^{\circ} \mathrm{C}$, por $1 \mathrm{~min}$, sem imersão posterior em água à temperatura ambiente (SMIDERLE et al., 2005).

Diante do exposto, o objetivo deste trabalho foi determinar metodologias adequadas para a superação da dormência de sementes de catingueira.

\section{MATERIAL E MÉTODOS}

O experimento foi realizado no Laboratório de Análise de Sementes do Departamento de Fitotecnia do Centro de Ciências Agrárias da Universidade Federal da Paraíba, localizado em Areia, PB. As sementes de catingueira foram coletadas diretamente das árvores-matrizes na Caatinga paraibana e beneficiadas por meio de debulha manual.

Após o beneficiamento, as sementes foram submetidas aos seguintes tratamentos: testemunha $\left(\mathrm{T}_{1}\right)$, escarificação manual com lixa d'água $\mathrm{n}^{\circ} .80\left(\mathrm{~T}_{2}\right)$, desponte na região oposta à da emissão da radícula $\left(\mathrm{T}_{3}\right)$, imersão em ácido sulfúrico concentrado por 6 , 8 e $10 \mathrm{~min}\left(\mathrm{~T}_{4}, \mathrm{~T}_{5}\right.$ e $\mathrm{T}_{6}$, respectivamente), imersão em água à temperatura de 60,70 e $80{ }^{\circ} \mathrm{C}$ por $1 \mathrm{~min}\left(\mathrm{~T}_{7}\right.$, $\mathrm{T}_{8}$ e $\mathrm{T}_{9}$, respectivamente), imersão em água fria por 24,48 e $72 \mathrm{~h}\left(\mathrm{~T}_{10}, \mathrm{~T}_{11}\right.$ e $\mathrm{T}_{12}$, respectivamente $)$.

Depois de submetidas aos tratamentos prégerminativos, as sementes foram semeadas em bandejas plásticas perfuradas no fundo, contendo areia lavada, previamente peneirada e esterilizada em autoclave por um período de $2 \mathrm{~h}$ e $30 \mathrm{~min}$, a uma temperatura de 120 ${ }^{\circ} \mathrm{C}$, umedecida com quantidade de água equivalente a $60 \%$ da capacidade de retenção, cuja manutenção da umidade foi por meio de irrigações diárias.

Para avaliação do efeito dos tratamentos, determinaram-se as seguintes características: Emergência - foram utilizadas 100 sementes por tratamento, divididas em quatro sub-amostras de 25 . As contagens do número de sementes germinadas iniciaram-se aos cinco e estenderam-se até os 21 dias após a semeadura, utilizando-se como critério plântulas com os cotilédones acima do nível do solo, com os resultados calculados de acordo com Brasil (1992); Primeira contagem de emergência correspondente à porcentagem acumulada de plântulas

R. Árvore, Viçosa-MG, v.31, n.3, p.405-415, 2007 
normais até o $10^{\circ}$ dia após o início do teste; Índice de velocidade de emergência (IVE) - foram realizadas contagens diárias, durante 21 dias, das plântulas normais, cujo índice foi calculado conforme a fórmula proposta por Maguire (1962); Comprimento de plântulas - no final do teste de emergência, as plântulas normais de cada repetição foram medidas com o auxílio de uma régua graduada em centímetros, sendo os resultados expressos em centímetros por plântula; e Massa seca das plântulas - após a contagem final no teste de emergência, as plântulas foram secadas em estufa regulada a $80{ }^{\circ} \mathrm{C}$ por $24 \mathrm{~h}$ e, decorrido esse período, pesadas em balança analítica com precisão de $0,001 \mathrm{~g}$, conforme recomendações de Nakagawa (1999).

O delineamento experimental utilizado foi o inteiramente ao acaso, constando de 12 tratamentos de superação da dormência. Os dados foram submetidos à análise de variância, e a comparação entre as médias foi feita pelo teste de Tukey a $5 \%$ de probabilidade, quando houve significância no teste $\mathrm{F}$, em que se utilizou o software ESTAT, versão 2.0/2001.

\section{RESULTADOS E DISCUSSÃO}

De acordo com os dados das Tabelas 1 e 2, referentes ao resumo da análise de variância, verificou-se que houve efeito significativo dos tratamentos de superação da dormência em todas as variáveis analisadas (emergência, primeira contagem, índice de velocidade de emergência, comprimento e massa seca da raiz e parte aérea).

Na Figura 1, encontram-se os dados referentes às porcentagens de emergência de plântulas de catingueira oriundas de sementes submetidas a diferentes tratamentos pré-germinativos, em que se verificaram maiores valores nos tratamentos de imersão em ácido sulfúrico por 8 e $10 \mathrm{~min}\left(\mathrm{~T}_{5}\right.$ e $\mathrm{T}_{6}$, respectivamente), que não diferiram estatisticamente entre si, como também da escarificação manual com lixa $\left(\mathrm{T}_{2}\right)$, imersão no ácido sulfúrico por 6 min $\left(\mathrm{T}_{4}\right)$ e imersão em água a 70 e 80 ${ }^{\circ} \mathrm{C}\left(\mathrm{T}_{8}\right.$ e $\mathrm{T}_{9}$, respectivamente).

Como as escarificações mecânica e química e a imersão em água quente provocam fissuras no tegumento, aumentando a permeabilidade e permitindo a embebição e, conseqüentemente, o início da emergência, esses resultados evidenciam a ocorrência de dormência causada pela impermeabilidade do tegumento. Assim, fica comprovada a eficiência desses tratamentos em romper a camada impermeável das sementes, possibilitando a absorção de água e, conseqüentemente, uma emergência mais rápida e uniforme. Resultados semelhantes foram obtidos por Smiderle e Souza (2003), quando verificaram que a escarificação com ácido sulfúrico por $5 \mathrm{~min}$, revelou ser o método mais efetivo para a superação da dormência de sementes de Bowdichia virgilioides Kunth. Alves et al. (2006) também constataram a eficiência do tratamento químico com ácido sulfúrico concentrado por períodos entre 74 e 115 min na superação da dormência de unidades de dispersão de Zizyphus joazeiro Mart.

Quanto à eficiência da escarificação mecânica, Medeiros Filho et al. (2002) relataram que Operculina macrocarpa (L.) Farwel. apresenta sementes dormentes, destacandose a escarificação mecânica como o método mais eficiente para a sua superação. Roversi et al. (2002) também observaram que a escarificação mecânica foi o tratamento mais eficiente para a superação da dormência em sementes de Acacia mearnsii Willd. De forma semelhante, Alves et al. (2004) obtiveram as maiores porcentagens de emergência de plântulas de Bauhinia divaricata L. quando utilizaram a escarificação por meio do desponte na região oposta à micrópila. Piroli et al. (2005) trabalhando com sementes de Peltophorum dubium (Spreng.) Taub., obtiveram um porcentual de germinação de $89 \%$ quando utilizaram a escarificação mecânica.

Tabela 1 - Resumo das análises de variância da emergência, da primeira contagem e do índice de velocidade de emergência (IVE) de plântulas de catingueira oriundas de sementes submetidas a diferentes tratamentos pré-germinativos

Table 1 - Summary of variance analysis for emergence, first count and index of catingueira seedling emergence speed of seeds subjected to different pre-germinative treatments

\begin{tabular}{lccc}
\hline Fontes de Variação & GL & & Quadrado Médio \\
\cline { 2 - 4 } & & Emergência & Primeira contagem \\
\hline Tratamentos & 11 & $1777,1572 * *$ & $1175,1364 * *$ \\
Resíduo & 36 & 83,5347 & 75,0139 \\
CV $(\%)$ & - & 15,36 & 24,92 \\
DMS & - & 22,54 & 21,36 \\
\hline
\end{tabular}

** significativo $(\mathrm{P}<0,01)$ pelo teste $\mathrm{F}$.

R. Árvore, Viçosa-MG, v.31, n.3, p.405-415, 2007 
Tabela 2 - Resumo das análises de variância do comprimento da raiz primária, da parte aérea e das raízes e da parte aérea de plântulas de catingueira oriundas de sementes submetidas a diferentes tratamentos pré-germinativos

Table 2 - Summary of analysis of variance for height of primary root and aerial part, and dry mass of primary root and aerial part of catingueira seedlings derived from seeds subjected to different germinative treatments

\begin{tabular}{|c|c|c|c|c|c|}
\hline \multirow[t]{3}{*}{ Fontes de Variação } & \multirow[t]{3}{*}{ GL } & \multicolumn{4}{|c|}{ Quadrado Médio } \\
\hline & & \multicolumn{2}{|c|}{ Comprimento $(\mathrm{cm})$} & \multicolumn{2}{|c|}{ Massa seca (g/plântula) } \\
\hline & & Raiz primária & Parte aérea & Raízes & Parte aérea \\
\hline Tratamentos & 11 & $21,1396 * *$ & $2,4143 * *$ & $0,0000 * *$ & $0,0011 * *$ \\
\hline Resíduo & 36 & 1,3949 & 0,2437 & 0,0000 & 0,0001 \\
\hline $\mathrm{CV}(\%)$ & - & 11,32 & 5,05 & 29,74 & 10,49 \\
\hline DMS & - & 2,91 & 1,22 & 0,006 & 0,027 \\
\hline
\end{tabular}

** significativo $(\mathrm{P}<0,01)$ pelo teste $\mathrm{F}$.

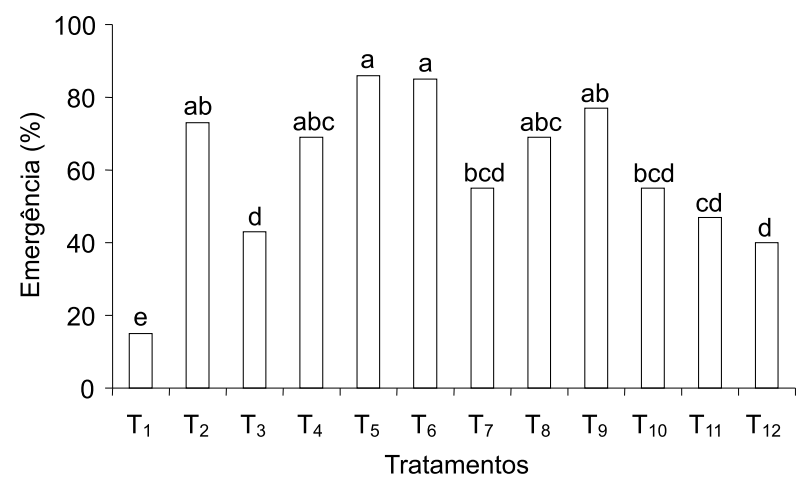

Testemunha ( $\left.T_{1}\right)$, escarificação com lixa, $\left(T_{2}\right)$, desponte $\left(T_{3}\right)$, imersão em ácido sulfúrico por 6,8 e $10 \mathrm{~min}\left(\mathrm{~T}_{4}, \mathrm{~T}_{5}\right.$ e $\mathrm{T}_{6}$, respectivamente), imersão em água a 60,70 e $80{ }^{\circ} \mathrm{C}\left(\mathrm{T}_{7}, \mathrm{~T}_{8}\right.$ e $\mathrm{T}_{9}$, respectivamente) e imersão em água fria por 24,48 e $72 \mathrm{~h}\left(\mathrm{~T}_{10}, \mathrm{~T}_{11} \mathrm{e} \mathrm{T}_{12}\right.$, respectivamente). Médias seguidas de mesma letra não diferem estatisticamente entre si, pelo teste de Tukey a $5 \%$.

Intact seeds (T1), scarification with sandpaper, (T2), cutting (T3), immersion in sulfuric acid for 6,8 and 10 minutes $(T 4, T 5$ and T6, respectively), immersion in water 60,70 and $80^{\circ} \mathrm{C}(T 7, T 8$ and $T 9$, respectively), immersion in cold water for 24,48 and 72 hours (T10, T11 and T12, respectively).

Means followed by same letter were not statistically different by the Tukey test at 5\%.

Figura 1 - Emergência de plântulas de catingueira oriundas de sementes submetidas a diferentes tratamentos pré-germinativos.

Figure 1 -Emergence of catingueira seedlings derived from seeds subjected to different pre-germinative treatments.

Em relação aos tratamentos com água quente, Oliveira et al. (2003) relataram que a imersão das sementes de Peltophorum dubium (Spreng.) Taubert. em água, à temperatura de $95^{\circ} \mathrm{C}$ e posterior permanência na mesma água por mais $24 \mathrm{~h}$, fora do aquecimento foi eficiente na promoção da germinação, sendo prático e dispensando o uso de tratamentos de desinfestação. Smiderle et al. (2005) também constataram que a emergência máxima de plântulas de Acacia mangium Willd. foi obtida após o tratamento das sementes em água a $100{ }^{\circ} \mathrm{C}$ por $1 \mathrm{~min}$, sem imersão posterior em água à temperatura ambiente.

A imersão em água quente não foi, no entanto, eficiente para a superação da dormência de sementes de Stryphnodendron pulcherrimum (Willd.) Hochr (VARELA et al., 1991), Mimosa caesalpiniaefolia Benth. (MARTINS et al., 1992), Copaifera langsdorffii (PEREZ e PRADO, 1993), Senna macranthera (Colladon.) Irwin \& Barneby (SANTARÉM e ÁQUILA, 1995), Trifolium repens L. (MEDEIROS e NABINGER, 1996), Bauhinia monandra Britt. e Bahunia ungulata L. (ALVES et al., 2000), Mimosa caesalpiniaefolia Benth. (BRUNO et al., 2001), Bauhinia divaricata L. (ALVES et al., 2004) e de Peltophorum dubium (Spreng.) Taub (OLIVEIRA et al., 2003; PIROLI et al., 2005).

De acordo com os dados da primeira contagem (Figura 2), verificou-se que a maior média ocorreu no tratamento com escarificação manual com lixa $\left(\mathrm{T}_{2}\right)$, sendo que os demais apresentaram desempenhos inferiores. Constatou-se, assim, a eficiência da escarificação mecânica em provocar fissuras no tegumento das sementes, eliminando a impermeabilidade do tegumento destas. No entanto, Medeiros Filho et al. (2002) relataram que a escarificação mecânica pode ocasionar injúrias nas sementes pela fricção ou diferença de constituição de seus tegumentos em função da espécie. Ainda segundo esses autores, a utilização de material abrasivo exige cuidados quanto à intensidade e à forma de aplicação, para não comprometer a qualidade das sementes.

Os demais tratamentos (imersão em ácido sulfúrico, águas quente e fria por diferentes períodos, bem como o desponte na região oposta à da emissão da radícula) não foram eficientes, pois não permitiram que as sementes expressassem seu máximo potencial fisiológico (Figura 2). Diante desses resultados, constatou-se que esse 
teste de vigor indicou que os tratamentos que proporcionaram uma porcentagem de emergência satisfatória (imersão em ácido sulfúrico por 6, 8 e 10 min, escarificação manual com lixa, imersão em água a 70 e $80^{\circ} \mathrm{C}$ ) comprometeram, de certa forma, o vigor das sementes. Resultados diferentes foram relatados por Bruno et al. (2001), quando constataram a eficiência do ácido sulfúrico no tratamento pré-germinativo de sementes de Mimosa caesalpiniaefolia Benth., cujo melhor resultado na primeira contagem de emergência ocorreu com a imersão por períodos entre 10 e 13 min. Alves et al. (2006) também obtiveram uma emergência em plântulas de Zizyphus joazeiro Mart. de 50\%, por ocasião da primeira contagem com o emprego de ácido sulfúrico concentrado por $110 \mathrm{~min}$.

Quanto ao índice de velocidade de emergência (Figura 3), os maiores valores foram obtidos com as sementes do tratamento de escarificação manual com lixa $\left(\mathrm{T}_{2}\right)$, no entanto não diferiram estatisticamente da imersão no ácido sulfúrico por 8 e $10 \mathrm{~min},\left(\mathrm{~T}_{5}\right.$ e $\mathrm{T}_{6}$, respectivamente), bem como da imersão em água a 80 ${ }^{\circ} \mathrm{C}\left(\mathrm{T}_{9}\right)$, enquanto os demais apresentaram desempenhos inferiores. Esse teste de vigor apresentou resultados semelhantes àqueles da emergência, mostrando-se mais eficiente em predizer o vigor das sementes submetidas aos diversos tratamentos pré-germinativos.

Lopes et al. (1998) obtiveram maior velocidade de emergência de plântulas de Caesalpinia ferrea Mart. quando as sementes foram submetidas ao ácido sulfúrico concentrado por $60 \mathrm{~min}$. Sampaio et al. (2001) também constataram maior velocidade de emergência em plântulas de Bowdichia virgilioides com sementes imersas no ácido sulfúrico por períodos entre 8 e $11 \mathrm{~min}$. De forma semelhante, Barbosa et al. (2004) verificaram que as porcentagens de germinação de sementes de Ochroma lagopus SW., nos tratamentos com água a $80^{\circ} \mathrm{C}$ e com ácido sulfúrico concentrado por $1 \mathrm{~min}$ ou $1 / 2 \mathrm{~min}$, produziram as maiores porcentagens e índices de velocidade de germinação.

A escarificação mecânica provoca fissuras no tegumento das sementes, aumentando, assim, a sua permeabilidade e, conseqüentemente, facilitando a embebição e a aceleração do início do processo de germinação (FRANKE e BASEGGIO, 1998). Portanto, o tratamento $\mathrm{T}_{2}$ (escarificação manual com lixa) constituise num método prático e eficiente, uma vez que proporcionou maior velocidade de emergência (Figura 3).

R. Árvore, Viçosa-MG, v.31, n.3, p.405-415, 2007

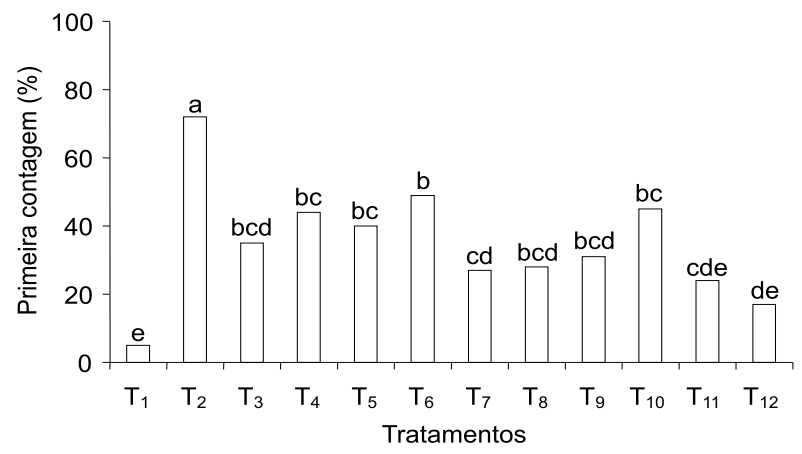

Testemunha ( $\left.T_{1}\right)$, escarificação com lixa, $\left(T_{2}\right)$, desponte $\left(T_{3}\right)$, imersão em ácido sulfúrico por 6,8 e $10 \mathrm{~min}\left(\mathrm{~T}_{4}, \mathrm{~T}_{5} \mathrm{e} \mathrm{T}_{6}^{2}\right.$, respectivamente), imersão em água a 60,70 e $80{ }^{\circ} \mathrm{C}\left(\mathrm{T}_{7}, \mathrm{~T}_{8}\right.$ e $\mathrm{T}_{9}$, respectivamente) e imersão em água fria por 24,48 e $72 \mathrm{~h}\left(\mathrm{~T}_{10}, \mathrm{~T}_{11}\right.$ e $\mathrm{T}_{12}$, respectivamente).

Médias seguidas de mesma letra não diferem estatisticamente entre si, pelo teste de Tukey a $5 \%$.

Intact seeds (T1), escarification with sandpaper, (T2), cutting (T3), immersion in sulfuric acid for 6,8 and 10 minutes (T4, T5 and T6, respectively), immersion in water 60,70 and $80^{\circ} \mathrm{C}(\mathrm{T} 7, \mathrm{~T} 8$ and $T 9$, respectively), immersion in cold water for 24, 48 and 72 hours (T10, T11 and T12, respectively). Means followed by same letter were not statistically different by the Tukey test at $5 \%$.

Figura 2 - Primeira contagem de emergência de plântulas de catingueira oriundas de sementes submetidas a diferentes tratamentos pré-germinativos.

Figure 2 - First emergence count of catingueira seedlings derived from seeds subjected to different pregerminative treatments

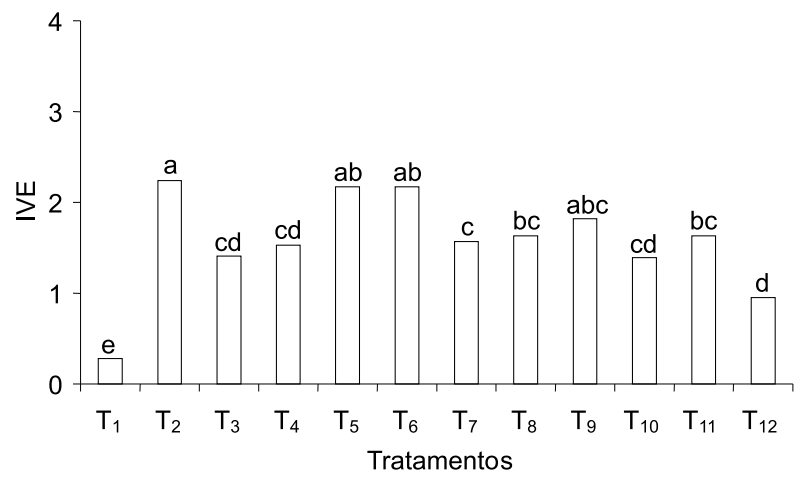

Testemunha $\left(\mathrm{T}_{1}\right)$, escarificação com lixa, $\left(\mathrm{T}_{2}\right)$, desponte $\left(\mathrm{T}_{3}\right)$, imersão em ácido sulfúrico por 6,8 e $10 \mathrm{~min}\left(\mathrm{~T}_{4}, \mathrm{~T}_{5}\right.$ e $\mathrm{T}_{6}$, respectivamente), imersão em água a 60,70 e $80{ }^{\circ} \mathrm{C}\left(\mathrm{T}_{7}, \mathrm{~T}_{8} \mathrm{e} \mathrm{T}_{9}\right.$, respectivamente) e imersão em água fria por 24,48 e $72 \mathrm{~h}\left(\mathrm{~T}_{10}, \mathrm{~T}_{1}\right.$ e $\mathrm{T}_{12}$, respectivamente).

Médias seguidas de mesma letra não diferem estatisticamente entre si, pelo teste de Tukey a $5 \%$.

Intact seeds (T1), scarification with sandpaper, (T2), cutting (T3), immersion in sulfuric acid for 6,8 and 10 minutes (T4, T5 and T6, respectively), immersion in water 60,70 and $80^{\circ} \mathrm{C}(T 7, T 8$ and T9, respectively), immersion in cold water for 24, 48 and 72 hours (T1O, T11 and T12, respectively). Means followed by same letter were not statistically different by the Tukey test at $5 \%$.

Figura 3 - Índice de velocidade de emergência de plântulas de catingueira oriundas de sementes submetidas a diferentes tratamentos pré-germinativos.

Figure 3-Index of emergence speed of catingueira seedlings derived from seeds subjected to different pregerminative treatments. 
A eficiência da escarificação mecânica foi também constatada por Franke e Baseggio (1998) para Desmodium incanum DC., Medeiros e Nabinger (1996) para Adesmia muricata (Jacq.) DC. e Trifolium resupinatum L. e Martins et al. (1997) para Desmodium tortuosum (Sw.) DC., cujas sementes apresentam características de dureza. Entretanto, esse tratamento não se mostrou eficiente na superação da dormência de sementes de Lathyrus nervosus Lam. (FRANKE eBASEGGIO, 1998).

Comparando as médias referentes ao comprimento da raiz primária(Figura 4), pôde-se verificar que os maiores valores foram obtidos com as plântulas oriundas das sementes submetidas aos tratamentos de desponte na região oposta à da radícula $\left(\mathrm{T}_{3}\right)$, imersão em água $\mathrm{a} 80^{\circ} \mathrm{C}$ por 1 minuto $\left(\mathrm{T}_{9}\right)$ e imersão em água fria por $72 \mathrm{~h}\left(\mathrm{~T}_{12}\right)$. No entanto, não diferiram estatisticamente da escarificação manual com lixa $\left(\mathrm{T}_{2}\right)$ e imersão em ácido sulfúrico por 8 e 10 min $\left(\mathrm{T}_{5} \mathrm{e} \mathrm{T}_{6}\right.$, respectivamente). Com relação ao comprimento da parte aérea (Figura 5), os valores máximos foram alcançados quando se empregou o tratamento de imersão em água a $80^{\circ} \mathrm{C}\left(\mathrm{T}_{9}\right)$, embora não tenha diferido estatisticamente dos tratamentos de escarificação manual com lixa $\left(\mathrm{T}_{2}\right)$, de imersão no ácido sulfúrico por $6 \mathrm{~min}\left(\mathrm{~T}_{4}\right)$, de imersão em água a 60 e $70^{\circ} \mathrm{C}$ $\left(\mathrm{T}_{7}\right.$ e $\mathrm{T}_{8}$, respectivamente) e de imersão em água fria por $48 \mathrm{~h}\left(\mathrm{~T}_{11}\right)$.

Pelos resultados do teste de comprimento de plântulas de catingueira (raiz primária e parte aérea), observou-se que esse teste também foi eficiente na distinção do vigor das sementes submetidas a diferentes tratamentos para superar a dormência, uma vez que foram semelhantes aos dados de emergência.

Lima e Garcia (1996) obtiveram plântulas de Acacia mangium com maior comprimento quando as sementes foram submetidas ao tratamento de imersão em água à temperatura de $80^{\circ} \mathrm{C}$ até atingir a temperatura ambiente $(2 \mathrm{~h})$. Já Gonçalves et al. (2006) verificaram maior comprimento de plântulas de Mimosa caesalpiniaefolia Benth. quando utilizaram a escarificação mecânica.

Alves et al. (2004) observaram que o comprimento das plântulas de Bauhinia divaricata L. não foi uma característica muito afetada pelos tratamentos utilizados, em que os maiores valores foram obtidos com as sementes dos tratamentos de desponte na região oposta à micrópila e da testemunha (sementes intactas). Os referidos autores informaram, ainda, que resultados inferiores de comprimento da raiz primária e parte aérea foram obtidos nos tratamentos de imersão no ácido sulfúrico concentrado por 10 min, imersão em água à temperatura de $80^{\circ} \mathrm{C}$ e imersão em água fria por $48 \mathrm{~h}$.

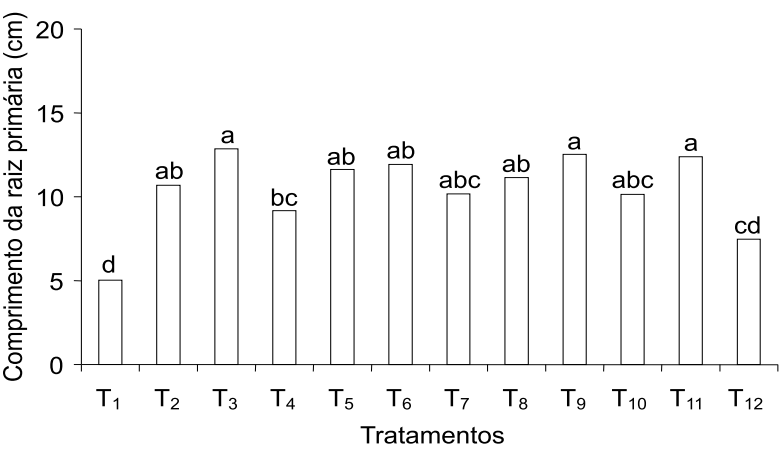

Testemunha( $\left.T_{1}\right)$, escarificaçãocomlixa, $\left(T_{2}\right)$, desponte $\left(T_{3}\right)$,imersãoemácidosulfúrico por $6,8 \mathrm{e} 10 \mathrm{~min}\left(\mathrm{~T}_{4}, \mathrm{~T}_{5} \mathrm{eT}_{6}\right.$, respectivamente), imersão em água $60,70 \mathrm{e} 80^{\circ} \mathrm{C}$ $\left(\mathrm{T}_{7}, \mathrm{~T}_{8} \mathrm{e} \mathrm{T}_{9}\right.$, respectivamente) e imersão em água fria por $24,48 \mathrm{e} 72 \mathrm{~h}\left(\mathrm{~T}_{10}, \mathrm{~T}_{11}\right.$ $\mathrm{e} \mathrm{T}_{12}$, respectivamente).

Médias seguidas de mesma letra não diferem estatisticamente entre si, pelo teste de Tukey a $5 \%$ de probabilidade.

Intact seeds (T1), scarification with sandpaper, (T2), cutting (T3), immersion in sulfuric acid for 6, 8 and 10 minutes (T4, T5 and T6, respectively), immersion in water 60,70 and $80^{\circ} \mathrm{C}(T 7, T 8$ and $T 9$, respectively), immersion in cold water for 24,48 and 72 hours (T1O, T11 and T12, respectively).

Means followed by same letter were not statistically different by the Tukey test at $5 \%$.

Figura 4 - Comprimento da raiz primária de plântulas de catingueira oriundas de sementes submetidas a diferentes tratamentos pré-germinativos.

Figure 4-Length of primary root of catingueira seedlings, derived from of seeds subjeted to different pregerminative treatments.

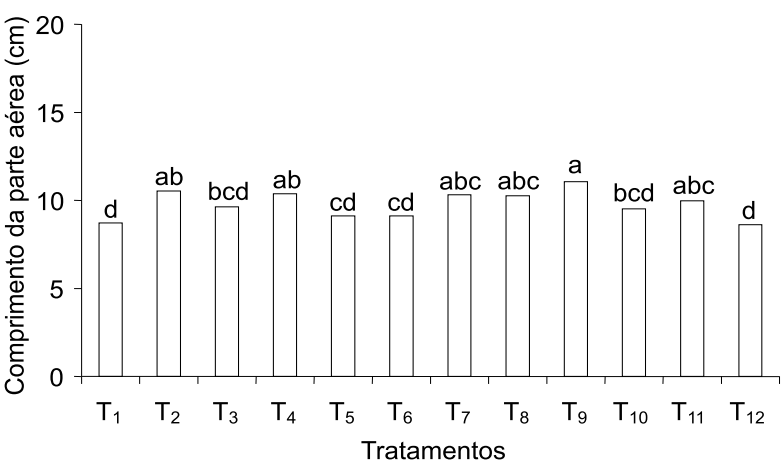

Testemunha ( $\left.\mathrm{T}_{1}\right)$, escarificação com lixa, $\left(\mathrm{T}_{2}\right)$, desponte $\left(\mathrm{T}_{3}\right)$, imersão em ácido sulfúrico por 6,8 e $10 \mathrm{~min}\left(\mathrm{~T}_{4}, \mathrm{~T}_{5} \mathrm{e} \mathrm{T}_{6}\right.$, respectivamente), imersão em água a 60,70 e $80^{\circ} \mathrm{C}\left(\mathrm{T}_{7}, \mathrm{~T}_{8} \mathrm{e}^{4} \mathrm{~T}_{9}\right.$, respectivamente) e imersão em água fria por 24,48 e 72 horas $\left(\mathrm{T}_{10}, \mathrm{~T}_{11} \mathrm{e} \mathrm{T}_{12}\right.$, respectivamente).

Médias seguidas de mesma letra não diferem estatisticamente entre si, pelo teste de Tukey a $5 \%$

Intact seeds (T1), scarification with sandpaper, (T2), cutting (T3), immersion in sulfuric acid for 6,8 and 10 minutes (T4, T5 and T6, respectively), immersion in water 60,70 and $80^{\circ} \mathrm{C}(T 7, T 8$ and $T 9$, respectively), immersion in cold water for 24,48 and 72 hours (T10, T11 and T12, respectively). Means followed by same letter were not statistically different by the Tukey test at $5 \%$.

Figura 5 - Comprimento da parte aérea de plântulas de catingueira oriundas de sementes submetidas a diferentes tratamentos pré-germinativos.

Figure 5 - Length of aerial part of catingueira seedlings, derived from of seeds subjected to different pregerminative treatments.

R. Árvore, Viçosa-MG, v.31, n.3, p.405-415, 2007 
Em relação à massa seca das raízes das plântulas (Figura 6), verificaram-se melhores resultados com os tratamentos de imersão em água fria por 48 e $72 \mathrm{~h}\left(\mathrm{~T}_{11}\right.$ e $\mathrm{T}_{12}$, respectivamente), seguido dos tratamentos de desponte $\left(\mathrm{T}_{3}\right)$ e imersão em água fria por $24 \mathrm{~h}\left(\mathrm{~T}_{10}\right)$, enquanto os menores valores foram alcançados com as plântulas originadas de sementes da testemunha (sementes intactas). O maior conteúdo de massa seca da parte aérea (Figura 7) foi obtido com as plântulas oriundas das sementes do tratamento do desponte na região oposta à da radícula $\left(\mathrm{T}_{3}\right)$, entretanto não diferiu estatisticamente daquelas do tratamento de imersão em água fria por $48 \mathrm{~h}\left(\mathrm{~T}_{11}\right)$ Santos et al. (2004) obtiveram maior conteúdo de massa seca da parte aérea de plântulas de Sterculia foetida L., empregando escarificação mecânica mais $24 \mathrm{~h}$ de embebição em água a temperatura ambiente. Alves et al. (2004) também observaram maiores valores de massa seca de plântulas de Bauhinia divaricata $\mathrm{L}$. quando as sementes foram submetidas aos tratamentos de desponte na região oposta à micrópila e à imersão em água na temperatura de $70^{\circ} \mathrm{C}$.

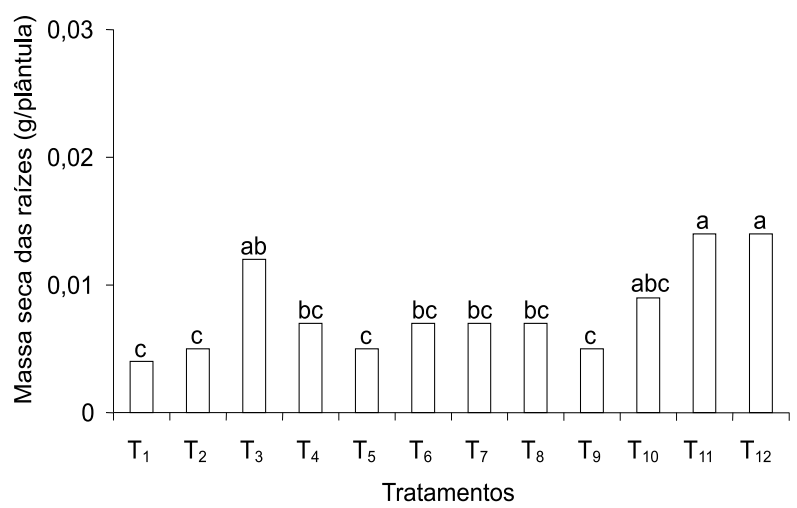

Testemunha ( $\left.T_{1}\right)$, escarificação com lixa, $\left(T_{2}\right)$, desponte $\left(T_{3}\right)$, imersão em ácido sulfúrico por 6,8 e 10 minutos $\left(\mathrm{T}_{4}, \mathrm{~T}_{5} \mathrm{e} \mathrm{T}_{6}\right.$, respectivamente), imersão em água a 60,70 e $80^{\circ} \mathrm{C}\left(\mathrm{T}_{7}, \mathrm{~T}_{8}\right.$ e $\mathrm{T}_{9}$, respectivamente) e imersão em água fria por 24,48 e $72 \mathrm{~h}\left(\mathrm{~T}_{10}, \mathrm{~T}_{11}\right.$ e $\mathrm{T}_{12}$, respectivamente). Médias seguidas de mesma letra não diferem estatisticamente entre si, pelo teste de Tukey a $5 \%$.

Intact seeds (T1), scarification with sandpaper, (T2), cutting (T3), immersion in sulfuric acid for 6, 8 and 10 minutes (T4, T5 and T6, respectively), immersion in water 60,70 and $80{ }^{\circ} \mathrm{C}(\mathrm{T} 7, \mathrm{~T} 8$ and T9, respectively), immersion in cold water for 24,48 and 72 hours (T10, T11 and T12, respectively).

Means followed by same letter were not statistically different by the Tukey test at $5 \%$.

Figura 6 - Massa seca das raízes de plântulas de catingueira oriundas de sementes submetidas a diferentes tratamentos pré-germinativos.

Figure 6-Root dry matter of catingueira seedlings, derived from of seeds subjected to different pre-germinative treatments.

R. Árvore, Viçosa-MG, v.31, n.3, p.405-415, 2007
Apesar de a água quente ser um método barato, que pode ser usado em larga escala, neste trabalho ela não permitiu um bom desenvolvimento das plântulas, uma vez que os tratamentos de imersão em água, nas temperaturas de 60,70 e $80{ }^{\circ} \mathrm{C}\left(\mathrm{T}_{7}, \mathrm{~T}_{8}\right.$ e $\mathrm{T}_{9}$, respectivamente), resultaram em menor conteúdo de massa (Figuras 6 e 7). Em experimento realizado com sementes de Mimosa caesalpiniaefolia Benth, Bruno et al. (2001) observaram que as sementes imersas em água fervente por 2 min originaram plântulas que continham menor conteúdo de matéria seca.

Os resultados dos testes de vigor, baseados no conteúdo de massa seca das plântulas, indicaram que estes não foram eficientes na indicação dos melhores tratamentos pré-germinativos, uma vez que foram contraditórios, em razão provavelmente, das perdas de material vegetal durante a sua determinação.

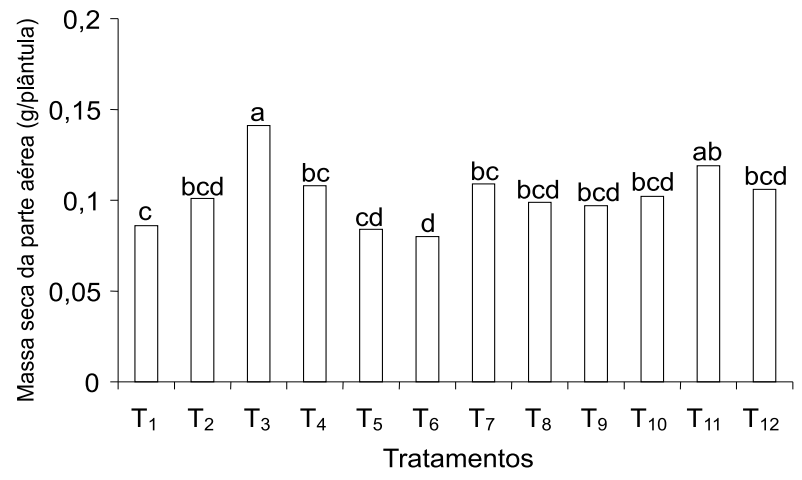

Testemunha ( $\left.T_{1}\right)$, escarificação com lixa, $\left(T_{2}\right)$, desponte $\left(T_{3}\right)$, imersão em ácido sulfúrico por 6,8 e $10 \mathrm{~min}\left(\mathrm{~T}_{4}, \mathrm{~T}_{5} \mathrm{e} \mathrm{T}_{6}\right.$, respectivamente), imersão em água a 60,70 e $80{ }^{\circ} \mathrm{C}\left(\mathrm{T}_{7}, \mathrm{~T}_{8} \mathrm{e} \mathrm{T}_{9}\right.$, respectivamente) e imersão em água fria por 24,48 e $72 \mathrm{~h}\left(\mathrm{~T}_{10}, \mathrm{~T}_{11}, \mathrm{e}_{12}\right.$, respectivamente).

Médias seguidas de mesma letra não diferem estatisticamente entre si, pelo teste de Tukey a $5 \%$.

Intact seeds (T1), scarification with sandpaper, (T2), cutting (T3), immersion in sulfuric acid for 6,8 and 10 minutes $(T 4, T 5$ and T6, respectively), immersion in water 60,70 and $80^{\circ} \mathrm{C}(T 7, T 8$ and $T 9$, respectively), immersion in cold water for 24, 48 and 72 hours (T10, T11 and T12, respectively). Means followed by same letter were not statistically different by the Tukey test at $5 \%$.

Figura 7 - Massa seca da parte aérea de plântulas de catingueira oriundas de sementes submetidas a diferentes tratamentos pré-germinativos.

Figure 7 - Dry mass of aerial part of catingueira seedlings, derived from of seeds subjected to different pregerminative treatments.

\section{CONCLUSÃO}

Para superação da dormência de sementes de catingueira, os tratamentos mais eficientes foram: escarificação manual com lixa, imersão em ácido sulfúrico concentrado por 8 e 10 min e imersão em água a $80^{\circ} \mathrm{C}$ por $1 \mathrm{~min}$. 


\section{AGRADECIMENTOS}

Ao CNPq, pela concessão das bolsas de Desenvolvimento Científico Regional (DCR) e PIBIC, e aos funcionários do Laboratório de Análise de Sementes Antônio Alves de Lima e Severino Francisco dos Santos pela colaboração na execução desse trabalho.

\section{REFERÊNCIAS}

ALVES, A.U. et al. Superação da dormência em sementes de Bauhinia divaricata L. Acta Botanica Brasilica, v.18, n.4, p.871-879, 2004.

ALVES, E. U. et al. Ácido sulfúrico na superação da dormência de unidades de dispersão de juazeiro (Zizyphus joazeiro Mart.). Revista Árvore, v.30, n.2, p.187-195, 2006.

ALVES, M. C. S. et al. Superação da dormência em sementes de Bauhinia monandra Britt. e Bauhinia ungulata L. - Caesalpinoideae.

Revista Brasileira de Sementes, v.22, n.2, p.139-144, 2000.

BARBOSA, A. P. et al.Tecnologia alternativa para a quebra de dormência das sementes de pau-debalsa (Ochroma lagopus SW., Bombacaceae). Acta Amazonica, v.34, n.1, p.107-110, 2004.

BERTALOT, M. J. A.; NAKAGAWA, J. Superação da dormência em sementes de Leucaena diversifolia (Schlecht.) Bentham K 156. Revista Brasileira de Sementes, v.20, n.1, p.39-42, 1998.

BIANCHETTI, A.; RAMOS, A. Quebra de dormência de sementes de guapuruvu (Schizolobium parahyba (Vellozo) Blake). Colombo: Embrapa/URPFCS, 1981. 22p.

(Documentos, 2).

BRAGA, R. Plantas do nordeste: especialmente do Ceará. Natal: Fundação Guimarães Duque, 1976. 509p. (Coleção Mossoroense, 42).

BRASIL. Ministério da Agricultura e Reforma Agrária. Regras para análise de sementes. Brasília: CLAV/DNDV/SNAD/MA, 1992. 365p.
BRUNO, R. L. A. et al. Tratamentos prégerminativos parar superar a dormência de sementes de Mimosa caesalpiniaefolia Benth. Revista Brasileira de Sementes, v.23, n.2, p.136-143, 2001.

CARVAlho, N. M.; NAKAGAWA, J. Sementes: ciência, tecnologia e produção. 4.ed. Jaboticabal: FUNEP, 2000. 429p.

CARVALHO, N. M. et al. Maturação fisiológica de sementes de amendoim-docampo. Revista Brasileira de Sementes, v.2, n.2, p.23-27, 1980.

CÍCERO, S. M. Dormência de sementes. In: SEMANA DE ATUALIZAÇÃO EM PRODUÇÃO DE SEMENTES, 1., 1986, Campinas. Trabalhos...Campinas: Fundação Cargill, 1986. p.41-76.

FRANKE, L. B.; BASEGGIO, J. Superação da dormência em sementes de Desmodium incanum DC. e Lathyrus nervosus Lam. Revista Brasileira de Sementes, v.20, n.2, p.420-424, 1998.

GONÇALVES, E. P. et al. Temperatura, beneficiamento e superação de dormência sobre o potencial fisiológico de sementes de sabiá (Mimosa caesalpiniaefolia). Sitientibus Série Ciências Biológicas, v.6, n.1, p.45-49, 2006.

INSTITUTO BRASILEIRO DO MEIO AMBIENTE - IB AMA. Sementes

florestais: colheita, beneficiamento e armazenamento. Brasília: 1998. 26p.

KRAMER, P. J.; KOZLOWISK, T. T. Fisiologia das árvores. Lisboa: Fundação Calouste Gubbenkian, 1972. 745p.

LIMA, D.; GARCIA, L. C. Avaliação de métodos para o teste de germinação em sementes de Acacia mangium Willd. Revista Brasileira de Sementes, v.18, n.2, p.180-185, 1996.

LOPES, J. C. et al. Germinação de sementes de espécies florestais de Caesalpinea ferrea Mart. ex Tul. var. leiostachya Benth., Cassia grandis L. e Samanea saman Merrill, após tratamentos para superar a dormência. Revista Brasileira de Sementes, v.20, n.1, p.80-86, 1998.

R. Árvore, Viçosa-MG, v.31, n.3, p.405-415, 2007 
LOPES, J. C.; DIAS, P. C.; MACEDO, C. M. P. Tratamentos para acelerar a germinação e reduzir a deterioração das sementes de Ormosia nitida Vog. Revista Árvore, v.30, n.2, p.171-177, 2006.

MAGUIRE, J. D. Speed of germination aid in selection and evaluation for seedling emergence and vigor. Crop Science, v.2, n.2, p.176-177, 1962.

MAIA, G. N. Catingueira. In: MAIA, G. N. Caatinga: árvores e arbustos e suas utilidades. São Paulo: Leitura e Arte, 2004. p.159-169.

MARTINS, C. C.; CARVALHO, N. M.; OLIVEIRA, A. P. Quebra de dormência de sementes de sabiá (Mimosa caesalpiniaefolia Benth.). Revista Brasileira de

Sementes, v.14, n.1, p.5-8, 1992.

MARTINS, C. C. et al. Superação da dormência de sementes de carrapicho-beiço-de-boi. Planta Daninha, v.15, n.2, p.104-113, 1997.

MAYER, A. M.; POLJAKOFF-MAYBER, A. The germination of seeds. 4.ed. New York: Pergamon Press, 1989. 270p.

MEDEIROS FILHO, S.; FRANÇA, E. A.; INNECCO, R. Germinação de sementes de Operculina macrocarpa (L.) Farwel e Operculina alata (Ham.) Urban. Revista Brasileira de Sementes, v.24, n.2, p.102-107, 2002.

MEDEIROS, R. B.; NABINGER, C. Superação da dormência em sementes de leguminosas forrageiras. Revista Brasileira de Sementes, v.18, n.2, p.1983-199, 1996.

NAKAGAWA, J. Testes de vigor baseados no desempenho das plântulas. In: KRZYZANOWSKI, F. C.; VIEIRA, R. D.; FRANÇA NETO, J. B. (Ed.). Vigor de sementes: conceitos e testes. Londrina: ABRATES, 1999. 21p.

NASSIF, S. M. L.; PEREZ, S. C. J. G. A. Germinação de sementes de amendoim-do-campo (Pterogyne nitens Tul.): influência dos tratamentos para superar a dormência e profundidade de semeadura.

Revista Brasileira de Sementes, v.19, n.2, p.171-178, 1997.

R. Árvore, Viçosa-MG, v.31, n.3, p.405-415, 2007
OLIVEIRA, L. M.; DAVIDE, A. C.;

CARVALHO, M. L. M. Avaliação de métodos para quebra da dormência e para a desinfestação de sementes de canafístula (Peltophorum dubium (Sprengel) Taubert). Revista Árvore, v.27, n.5, p.597-603, 2003.

PIO CÔRREA, M. Dicionário das plantas úteis do Brasil e das exóticas cultivadas. Rio de Janeiro: Ministério da Agricultura, 1984. v.2.777p.

PIROLI, E.L. et al. Germinação de sementes de canafístula Peltophorum dubium (Spreng.) Taub. tratadas para superação da dormência.

Colloquium Agrariae, v.1, n.1, p.13-18, 2005.

POPINIGIS, F. Fisiologia da semente. Brasília: AGIPLAN, 1985. 285p.

ROLSTON, M. P. Water impermeable seed dormancy. The Botanical Review, v.44, n.3, p.365-396, 1978.

ROVERSI, T. et al. Superação da dormência em sementes de acácia negra (Acacia mearnsii Willd.). Revista Brasileira de Agrociência, v.8, n.2, p. 161-163, 2002.

SAMPAIO, L. S. V. et al. Ácido sulfúrico na superação da dormência de sementes de sucupira preta (Bowdichia virgilioides H.B.K. - Fabaceae). Revista Brasileira de Sementes, v.23, n.1, p.184-190, 2001.

SANTARÉM, E. R.; AQUILA, M. E. A. Influência de métodos de superação de dormência e do armazenamento na germinação de sementes de Senna macranthera (Colladon) Irwin \& Barneby (Leguminosae). Revista Brasileira de Sementes, v.17, n.2, p.205-209, 1995.

SANTOS, T. O.; OLIVEIRA, T. G. M.; MATOS, V. P. Escarificação mecânica em sementes de chichá (Sterculia foetida L.). Revista Árvore, v.28, n.1, p.1-6, 2004.

SMIDERLE, O. J.; MOURÃO JUNIOR, M.; SOUSA, R. C. P. Tratamentos pré-germinativos em sementes de acácia. Revista Brasileira de Sementes, v.27, n.1, p.78-85, 2005. 
SMIDERLE, O. J.; SOUSA, R. C. P. Dormência em sementes de paricarana (Bowdichia virgilioides Kunth - Fabaceae - Papilionidae). Revista Brasileira de Sementes, v.25, n.2, p.48-52, 2003.

SOUZA, S. M.; DRUMOND, M. A.; SILVA, H. D. Estudo de métodos para superar a dormência de sementes de Piptadenia obliqua (Pers.) Macbr., Pithecellobium parvifolium (Wild.) Benth e Cassia excelsa Schard, Petrolina: Embrapa/CPATSA, 1980. 42p. (Boletim Técnico, 2).
VARELA, V. P.; BROCKI, E.; SÁ, S. T. V.

Tratamentos pré-germinativos de sementes de espécies florestais da Amazônia: IV. faveira, camuzê - Stryphnodendron pulcherrimum (Willd.) Hochr Leguminosae. Revista Brasileira de Sementes, v.13, n.2, p.87-90, 1991.

VAZQUEZ-YANES, C.; OROZCO-SEGOVIA,A. Patterns of seed longevity and germination in the tropical rainforest. Annual Review of Ecology and Systematics, v.24, p.69-87, 1993. 
